\title{
A METHOD FOR DETERMINING THE UTILISATION OF GLUCOSE BY MYCOPLASMAS
}

\author{
D. G. FF. EdWARD AND W. B. MoORE* \\ Public Health Laboratory, Dulwich Hospital, London SE22 8QF and \\ Wellcome Research Laboratories, Beckenham, Kent BR3 $3 B S$
}

EARLY descriptions of Mycoplasma bovigenitalium (Edward, 1950), M. agalactiae subsp. agalactiae (Edward, 1954) and M. agalactiae subsp. bovis (Hale et al., 1962 Jasper, Jain and Brazil, 1966) stated that these organisms do not metabolise glucose, but subsequently claims (Cottew and Leach, 1969) were made to the contrary. The latter, however, have now been withdrawn (Leach, 1973). They had been based on observations of fall in $p \mathrm{H}$ value, during growth of the organisms in medium containing glucose, but were invalidated by failure to use the necessary controls, employed by Aluotto et al. (1970) and recommended by the Subcommittee on the Taxonomy of the Mycoplasmatales (Subcommittee, 1972). Metabolic degradation of substances other than glucose may also lead to acid production; a fall in $p \mathrm{H}$ noted in a metabolism test with glucose as substrate is therefore not necessarily evidence of ability to metabolise this carbohydrate. So, for practical purposes, there is need for a relatively simple test that can monitor specifically the disappearance of glucose from growth medium.

\section{MATERIALS AND METHODS}

Mycoplasmas and their cultivation. The following strains were studied: Acholeplasma laidlawii, PG8 and PG9; M. mycoides subsp. capri, PG3; M. gallisepticum, S6; M. neurolyticum, strain A; M. bovingenitalium, PG11; $M$. agalactiae subsp. agalactiae, PG2; $M$. agalactiae subsp. bovis, "Donetta"; and $M$. gateae, CS.

The solid and liquid growth media have been described previously (Edward, 1947, 1971); unless otherwise stated these contained $10 \%(\mathrm{v} / \mathrm{v})$ of a $25 \%(\mathrm{w} / \mathrm{v})$ extract of baker's yeast (Hayflick, 1965).

Estimation of glucose utilisation. The strain under test was first subcultured daily, eight or more times, in liquid growth medium containing $1 \%(\mathrm{w} / \mathrm{v})$ D-glucose and $0.002 \%(\mathrm{w} / \mathrm{v})$ phenol red. It was then inoculated into 1.5 litres of fresh growth medium containing $1 \%$ glucose, but no phenol red, and incubated at $37^{\circ} \mathrm{C}$ for $1-2$ days. The culture was spun in an angle-head centrifuge at $3600 \mathrm{~g}$ for $45 \mathrm{~min}$. and most of the supernate was decanted aseptically, leaving a dense suspension of cells in a small volume of spent medium for use as inoculum. A portion of this inoculum-suspension was removed and titrated for colony forming units (CFU) per ml by a modification of the method of Miles, Misra and Irwin (1938). The remainder, 3-7 ml, was added to $20 \mathrm{ml}$ of liquid growth medium containing $2.5 \%(\mathrm{w} / \mathrm{v})$ yeast extract, $0.25 \%(\mathrm{w} / \mathrm{v}) \mathrm{D}$-glucose, $0.05 \mathrm{M}$ Tris buffer and $0.01 \mathrm{M} \mathrm{MgCl}_{2}$. In experiments on the effect of suspension density on glucose utilisation, the inoculum-suspension was diluted in serial 10-fold steps with the same growth medium as diluent. Immediately after inoculation, 3-ml samples were removed for determination of glucose by the glucose-oxidase method (Huggett and Nixon, 1957) in an auto-analyser (Trinder, 1969). Further samples were taken at selected intervals, during incubation at $37^{\circ} \mathrm{C}$ for 24 or $48 \mathrm{~h}$. Uninoculated control media, with or without glucose, showed no change in glucose content over the total period of any experiment.

Received 2 Jan. 1975; accepted 3 Feb. 1975.

* Requests for reprints should be sent to W. B. M., Protein Chemistry R and D, Wellcome Research Laboratories, Langley Court, Beckenham, Kent BR3 3BS.

J. MED. MICROBIOL.-VOL. 8 (1975) 


\section{RESULTS}

Mycoplasmas capable of utilising glucose. Preliminary experiments indicated the importance of using cell suspensions of adequate density. Initially, glucose utilisation could not be demonstrated with $M$. gallisepticum and $M$. neurolyticum, species known to metabolise glucose, but the density of the suspensions did not exceed $10^{7} \mathrm{CFU}$ per $\mathrm{ml}$. However, cell yield was considerably augmented after eight daily subcultures in growth medium containing glucose, and with suspensions of greater density it then proved possible to demonstrate uptake of glucose and to show that this increased with the time of incubation. With $M$. neurolyticum, at a density of $10^{10} \mathrm{CFU}$ per $\mathrm{ml}$, the loss of glucose from the medium increased from $15 \%$ at $2 \mathrm{~h}$ to $30 \%, 41 \%$ and finally $100 \%$ after 4,6 and $24 \mathrm{~h}$ respectively (fig. 1 ).

The relation between glucose utilisation and suspension density was next investigated. In early experiments with $A$. laidlawii, without serial daily passage in glucose-containing medium, the utilisation of glucose by suspensions of density of about $10^{6} \mathrm{CFU}$ per $\mathrm{ml}$ was $33 \%$. This degree of utilisation, by suspensions of similar density, was not exceeded even after eight serial subcultures of the organism in glucose-containing medium. However, dilution of the suspension in 10-fold steps produced a correspondingly uniform reduction in glucose utilisation, on a linear scale (fig. 2). Utilisation in excess of $66 \%$ could not be demonstrated, even with suspensions made after 18 subcultures and tested at a density of $2.7 \times 10^{9} \mathrm{CFU}$ per $\mathrm{ml}$ (fig. 2). On the other hand, $M$. mycoides subsp. capri, at a density of $4.7 \times 10^{8}$ CFU per ml used more than $90 \%$ of the glucose in the medium (fig. 3); the luxuriant growth of this organism made preliminary daily subculture in glucose-containing medium unnecessary. Dilution of the suspension produced a more rapid fall in glucose utilisation than in the case of $\boldsymbol{A}$. laidlawii. M. gallisepticum, after eight serial subcultures, utilised more than $90 \%$ of the glucose when tested at a density of $1.8 \times 10^{8} \mathrm{CFU}$ per ml. A reduction of the density by only 10-fold caused the utilisation to fall sharply to an insignificant level (fig. 3). $M$. neurolyticum required a 30 -fold increase in suspension density to achieve $90 \%$ utilisation (fig. 3); the inoculum was prepared from a 48-h-old culture after eight daily subcultures of the organism. With this organism, too, a 10-fold reduction in suspension density led to a sharp fall in the amount of glucose utilised.

Mycoplasmas incapable of utilising glucose. In experiments with $M$. gateae, a species incapable of metabolising glucose but capable of hydrolysing L-arginine, there was no demonstrable utilisation of glucose, even when suspension densities exceeded $10^{11}$ CFU per

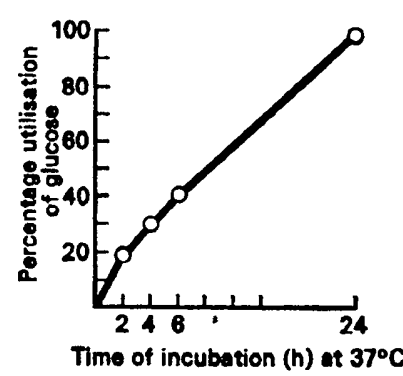

FIG. 1

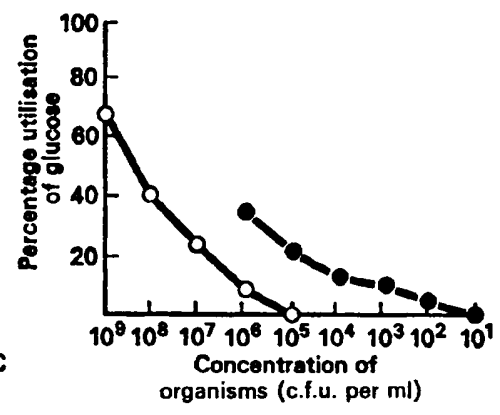

FIo. 2

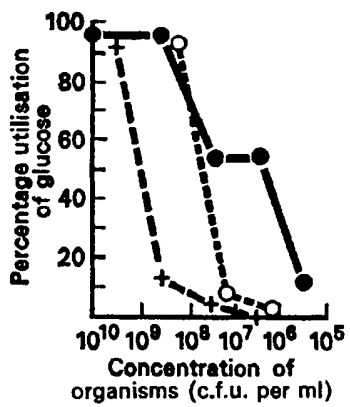

FIG. 3

FIG. 1.-Utilisation of D-glucose by Mycoplasma neurolyticum, at a concentration of $10^{10} \mathrm{CFU}$ per $\mathrm{ml}$, from a glucose-containing medium, during $24 \mathrm{~h}$ at $37^{\circ} \mathrm{C}$.

Fig. 2.-The effect of reducing the concentration of organisms on the glucose-utilising activity (during $24 \mathrm{~h})$ of Acholeplasma laidlawii. $O=$ Cells subcultured 18 times in $1 \%$ glucose medium; = cells subcultured eight times in $1 \%$ glucose medium.

FIG. 3.-The effect of reducing the concentration of organisms on the glucose-utilising activity of $M$. gallisepticum, $M$. mycoides subsp. capri and $M$. neurolyticum. $O=M$. gallisepticum; $+=M$. mycoides subsp. capri; $+=M$. neurolyticum. 
$\mathrm{ml}$ and an incubation period of $48 \mathrm{~h}$ was used. Negative results were also obtained with $M$. bovigenitalium, $M$. agalactiae subsp. agalactiae and $M$. agalactiae subsp. bovis, with suspension densities greater than $10^{9} \mathrm{CFU}$ per ml, during test periods of $48 \mathrm{~h}$. All these organisms were examined after eight daily subcultures in glucose-containing medium.

\section{Discussion}

The error of ascribing glucose-metabolising activity to $M$. bovigenitalium and the two subspecies of $M$. agalactiae was due, at least in part, to misinterpretation of the fall in $p \mathrm{H}$ of the test medium. Although $p \mathrm{H}$ change is a convenient indicator of general metabolic activity, it does not necessarily indicate utilisation of glucose in media containing this sugar. It may be due to the metabolism of compounds other than glucose, although our own unreported investigations have failed to incriminate specific amino acids, organic acids, purines and pyrimidines; supplementation of the medium with them, singly, failed to enhance the $p \mathrm{H}$ effect. This non-specific fall often exceeds half a $\mathrm{pH}$ unit, the minimal value indicative of glucose utilisation (Aluotto $e t$ al., 1970), and, with weak glucose fermenters, may actually mask acid production from glucose. Comparison of media with and without added yeast extract showed the fall to be greater in the presence of yeast extract, even when traces of glucose had been removed by treatment with glucose oxidase (by the method of T. Sander, personal communication). The use of metabolic tests involving a change in $p \mathrm{H}$ is therefore unreliable for determining glucose-utilising activity, particularly when the test organism can metabolise both glucose and arginine (Aluotto et al., 1970). A more specific technique is required to monitor the disappearance of any particular sugar from the medium.

Our experiments indicate that glucose uptake by glucose-metabolising mycoplasmas can be readily demonstrated by the glucose-oxidase method, and that reliable results require suspension densities above a critical minimum value, about $10^{9} \mathrm{CFU}$ per $\mathrm{ml}$, and a test incubation period of not less than $24 \mathrm{~h}$. The marked difference in maximum utilisation of glucose achieved by $M$. gallisepticum and $M$. neurolyticum (both $>90 \%$ ) and $A$. laidlawii $(66 \%)$, indicates a fundamental difference between these species. This may be the phosphoenolpyruvate-dependent phosphotransferase system that has been shown recently to be present in glucose-metabolising Mycoplasma spp. and absent from Acholeplasma spp. (Cirillo and Razin, 1973). The sharp fall in glucose utilisation that occurs when test suspensions of the glucose-metabolising mycoplasmas are diluted suggests the involvement of some soluble factor essential for the proper functioning of this degradative pathway.

\section{SUMMARY}

A technique for measuring glucose utilisation by mycoplasmas, in which the disappearance of glucose is monitored by the glucose-oxidase method, is proposed as an alternative to the $p \mathrm{H}$ method. For maximum reliability the number of organisms in the test suspension must exceed a critical minimum value. Differences in efficiency of glucose utilisation were demonstrated between species of Mycoplasma and Acholeplasma.

Our thanks are due to Professor Shmuel Razin for advice, and to Mr A. E. Pink and staff of the Wellcome Research Laboratories, Analytical Section, Department of Protein Chemistry, for performing the glucose analyses.

\section{REFERENCES}

Aluotto, B. B., Wittler, R. G., Williams, C. O. ANd Faber, J. E. 1970. Standardized bacteriological techniques for the characterization of Mycoplasma species. Int. J. syst. Bact., 20, 35.

CIRILLO, V. P. AND RazIN, S. 1973. Distribution of a phosphoenolpyruvate-dependent sugar phosphotransferase system in mycoplasmas. J. Bact., 113, 212.

Cortew, G. S. AND LeACH, R. H. 1969. Mycoplasmas of cattle, sheep and goats. In The Mycoplasmatales and the L-phase of bacteria, edited by L. Hayflick, New York, p. 527.

J. MED. MICROBIOL. - VoL. 8 (1975)

$2 \mathrm{H}$ 
EDWARD, D. G. FF. 1947. A selective medium for pleuropneumonia-like organisms. $J$. gen. Microbiol., 1, 238.

EDWARD, D. G. FF. 1950. An investigation of the biological properties of organisms of the pleuropneumonia group, with suggestions regarding the identification of strains. J. gen. Microbiol., 4, 311.

EDWARD, D. G. FF. 1954. The pleuropneumonia group of organisms: a review, together with some new observations. J. gen. Microbiol., 10, 27.

EDWARD, D. G. FF. 1971. Determination of sterol requirement for Mycoplasmatales. $J$. gen. Microbiol., 69, 205.

Hale, H. H., Helmboldt, C. F., Plastridge, W. N. and Stula, E. F. 1962. Bovine mastitis caused by a mycoplasma species. Cornell Vet., 52, 582.

HaYflick, L. 1965. Cell cultures and mycoplasmas. Tex. Rep. Biol. Med., 23, (suppl. 1), 285.

Huggett, A. St G. AND Nixon, D. A. 1957. Use of glucose oxidase, peroxidase and $o$-dianisidine in determination of blood and urinary glucose. Lancet, 2, 368.

JASPER, D. E., JAIN, N. C. AND BRAZIL, L. H. 1966. Clinical and laboratory observations on bovine mastitis due to Mycoplasma. J. Am. vet. med. Ass., 148, 1017.

LEACH, R. H. 1973. Further studies on classification of bovine strains of Mycoplasmatales, with proposals for new species, Acholeplasma modicum and Mycoplasma alkalescens. J. gen. Microbiol., 75, 135.

Miles, A. A., MiSRA, S. S. AND IRwin, J. O. 1938. The estimation of the bacterial power of the blood. J. Hyg., Camb., 38, 732.

SubCommittee on the taXoNOMY OF mycoplasmatales 1972. Proposal for minimum standards for description of new species of the order Mycoplasmatales. Int. J. syst. Bact., 22, 184.

TRINDER, P. 1969. Determination of blood glucose using an oxidase peroxidase system with a non-carcinogenic chromogen. J. clin. Path., 22, 158. 